Dialectic Volume I, Issue I: Front Matter

\title{
A New North American Design Research Organization
}

\author{
JOHN ZIMMERMAN ${ }^{1}$, CARLOS TEIXEIRA ${ }^{2}$, \\ ERIK STOLTERMAN ${ }^{3}$, JODI FORLIZZI ${ }^{1}$ \\ 1. Carnegie Mellon University \\ 2. Illinois Institute of Design \\ 3. Indiana University Bloomington
}

SUGGeSted CitATION: Forlizzi, J., Stolterman, E., Teizeira, C., \& Zimmerman, J. “A New North American Design

Research Organization.” Dialectic, 1.1 (2016): pgs. 14-17. DOI: http://dx.doi.org/10.3998/dialectic.14932326.0001.103 


\section{A New North}

\section{American}

\section{Design}

\section{Research}

\section{Organization}

JOHN ZIMMERMAN, CARLOS TEIXEIRA, ERIK STOLTERMAN \& JODI FORLIZZI

The last two decades have witnessed skyrocketing interest in design, designers, and design thinking. Businesses worked to promote and integrate design thinking into their innovation cultures (SAP, IBM, IDEO); tech companies purchased startups for their uX design teams; ${ }^{11}$ banks and other service enterprises purchased design consultancies to help spark innovation; ${ }^{2}$ and business consultancies acquired design agencies to extend their reach and offerings. ${ }^{3}$ This demand for design talent has helped drive rapid growth in professional master's programs focused on information design, UX design, service design, and strategy. Within several North American universities, designers joined English departments, information schools, computer science departments, and medical schools. These actions demonstrate the increasing importance that industry and the academy place on design and design thinking as it relates to and affects innovation.
Paralleling this growing interest in design, over the last two decades a new type of scholarly design research emerged, distinct from design studies and from the clinical design research conducted by practitioners. Referred to as both Research through Design and Constructive Design Research, this approach promotes design inquiry (making new things to make sense of the world) as a form of scholarly research, distinct from engineering and scientific research. ${ }^{4}$ When following this approach, researchers make things in order to reframe problematic situations, probe speculative futures, and reveal new preferred states; futures that could and should be. Technical advances, particularly around communication technology, have driven this growing interest in design.

\footnotetext{
Segall, L. (April 6, 2012) Silicon Valley is desperate for designers. CNNMoney Startup RADAR, Retrieved from http://money.cnn.com/2012/04/05/technology/ startups/designers/

2 Ha, A. (October 2, 2014) Design Firm Adaptive Path Acquired By Capital One. TechCrunch, Retrieved from https://techcrunch.com/2014/10/ozadaptive-path-acquired-by-capital-one/ 3 Hurst, N. (May 15, 2013) Big Corporations are Buying Design Firms in Droves. Wired, Retrieved from http://www.wired.com/2013/05/accenture-fjord/

4 Zimmerman, John, Jodi Forlizzi, and Shelley Evenson. (2007, April) Research through design as a method for interaction design research in $\mathrm{HCI}$. In Proceedings of the SIGCHI Conference on Human Factors in Computing Systems (pp. 493-502). ACM Press, http:// dx.doi.org/10.1145/1240624.1240704; Koskinen, Ilpo, John Zimmerman, Thomas Binder, and Johan Redström (2011) Design research through practice: From the lab, field, and showroom. Elsevier.
} 
Industry and departments outside of design want help from designers to make sense of what technology might be, to give it meaningful forms, and to envision how it can enrich people's lives.

Interestingly, the growing interest in design and design thinking as a driver of innovation has not led to increased funding for design research or a substantial investment in design education. Neither U.S. government agencies - the National Institutes of Health, the National Science Foundation, the Department of Education - nor foundations have turned to design practitioners, educators, or researchers for their expertise. Large-scale, interdisciplinary projects focused on wicked societal issues such as sustainability or obesity rarely, if ever, seek out the input of designers. The increased interest in design and design thinking has also had little impact on the number and size of design PhD programs in North America. These programs, which should be a locus for advancing design education and research, remain nearly non-existent.

To help address this situation, we are founding a design research organization for North America. These organizations and societies exist in Asia and Europe, providing a community for design researchers and educators and promoting PhDs in design. We envision an organization headquartered here in the U.S. that focuses on design education both within and outside of design schools, one that promotes the establishment and growth of PhD programs within design schools, and one that focuses on advancing constructive design research both here and around the world.

This organization would extend the growing impact of design by:

- Creating a viable, resilient community for design researchers and educators. This includes designers teaching and doing research in design schools, in academic departments outside of design, and in other organizations including industry, government, foundations, and NGOs. The organization would provide a venue for design researchers and educators to collectively generate priorities and share their latest advances.

- Mentoring universities to create PhD programs. The organization would help universities establish standards for a North American PhD in design, promote integration of design into interdisciplinary research, promote teaching of design skills and thinking to students in many other fields, and help to develop mechanisms for funding PhD work.

- Facilitating research opportunities. The organization would lobby government, industry, and foundations as funding sources for design research and education, promoting the benefits of design as a mode of inquiry by showing the impact it has made. In addition, the organization would facilitate linking design researchers with large-scale interdisciplinary projects that would benefit from input provided by design thinking experts.

- Bridging design research, education, and practice. The organization would provide a venue for practitioners to discuss changing needs that affect design education, and the persistent challenges faced in practice that re-search rarely addresses. Design educators could share best practices, especially around teaching new practices and advances in the learning sciences related to design. Design researchers could share their latest findings related to practice and education, and they could collectively generate research priorities with input from education and practice experts.

Readers of and contributors to Dialectic, this new journal being published by and for the AIGA Design Educators Community (DEC), are experts in communication and information design education, and therefore must play a critical role in creating this organization. This new Design Research organization needs your expertise to address emerging challenges around big data, information visualization, and the need to effectively facilitate collaboration between machine learning systems and people. Communication and information designers will shape the future through development of dashboards that help people make sense of data, through 
invention of new communication forms that harmonize dynamic data, text, images, audio, and video. These designers also have the capacity to further affect positive change by reframing how people read, communicate, coordinate, collaborate, and critique in small groups and at city, country, and global scales.

We will launch this new North American Design Research Organization at the IASDR 2017 Conference hosted by the University of Cincinnati from October 31 to November 3, 2017. <http://www.iasdr2017.com/>. Until then, there is much work to do to understand the needs of the North American design research, education and practice communities. We would love for you to contribute to a broadly informed dialogue to share your ideas, your hopes, your concerns, and your fears.

Join the conversation: \#NA_DRO

\section{References}

Ha, Anthony. (October 2, 2014) Design Firm Adaptive Path Acquired By Capital One. TechCrunch, Retrieved from https://techcrunch.com/2014/10/02 adaptive-path-acquiredby-capital-one/

Hurst, Nathan. (May 15, 2013) Big Corporations are Buying Design Firms in Droves. Wired, Retrieved from http://www. wired.com/2013/05/accenture-fjord/

Koskinen, Ilpo, John Zimmerman, Thomas Binder, and Johan Redström (2011) Design research through practice: From the lab, field, and showroom. Elsevier.

SAP (2016) Design Thinking with SAP, Retrieved from https:// designthinkingwithsap.com/

Segall, Laurie. (April 6, 2012) Silicon Valley is desperate for designers. CNNMoney Startup RADAR, Retrieved from http:// money.cnn.com/2012/04/05/technology/startups/designers/
Zimmerman, John, Jodi Forlizzi, and Shelley Evenson. (2007, April) Research through design as a method for interaction design research in $\mathrm{HCl}$. In Proceedings of the SIGCHI Conference on Human Factors in Computing Systems (pp. 493502). ACM Press, http://dx.doi.org/10.1145/1240624.1240704 
